\title{
BEHÇET HASTALIĞINDA DERI VE MUKOZA BELIRTILERi
}

\author{
Mucocutaneous Manifestations of Behcet's Disease
}

Emine Çölgeçen ${ }^{1}$, Kemal Özyurt ${ }^{2}$, Murat Borlu ${ }^{3}$

\section{ÖZET}

'Bozok Üniversitesi Tip Fakültesi, Dermatoloji Ana Bilim Dalı, Yozgat

${ }^{2}$ Kayseri Eğitim ve Araştrma Hastanesi Dermatoloji Kliniği, Kayseri

${ }^{3}$ Erciyes Üniversitesi Tip Fakültesi, Dermatoloji Ana Bilim Dalı, Kayseri

Emine Çölgeçen, Yrd. Doç. Dr. Kemal Özyurt, Uzm. Dr. Murat Borlu, Prof. Dr.

İletişim:

Yrd. Doç. Dr. Emine Çölgeçen Bozok Üniversitesi Tıp Fakültesi Dermatoloji Ana Bilim Dalı 66000 Yozgat

Tel: 035421270 60-3118

e-mail:

drecolgecen@hotmail.com

Geliş tarihi/Received:11.11.2013 Kabul tarihi/Accepted:09.05.2014

Bozok Tip Derg 2014,4(2):53-8 Bozok Med J 2014;4(2):53-8
Behçet hastalığı rekürren oral ve genital ülserler, oküler ve kutanöz lezyonlar, artrit ve vasküler tutulum ile karakterize kesin nedeni bilinmeyen multisistem inflamatuar bir hastalıktır. Tekrarlayıcı nitelikteki oral ve genital ülserler, eritema nodozum benzeri lezyonlar ve papülopüstüler lezyonlar başta olmak üzere çeşitli deri ve mukoza bulguları gösteren hastalığın tanısında da bu bulguların kritik önemi bulunmaktadır. Ayrıca, Behçet hastalığındaki mukokutanöz bulguların diğer ciddi organ tutulumlarına göre prognostik belirleyici özellikleri olmamasına karşın, hastaların yaşam kalitesini etkiledikleri açıktır. Bu derlemede Behçet hastalığının deri ve mukoza belirtileri anlatılmaktadır.

Anahtar Kelimeler: Behçet hastalığı; Mukokutanöz lezyonlar; Deri.

\section{ABSTRACT}

Behcet's disease is a multi-system inflammatory disorder of unknown origin, characterized by recurrent oral and genital ulcerations, ocular and cutaneous lesions, arthritis and vascular disease. Various mucocutaneous manifestations consisting mainly of recurrent oral and genital ulcerations, erythema nodosum like lesions and papulopustular lesios constitute the hallmark of Behcet's disease and diagnostic criteria rely heavily on these symptoms. In addition, although the mucocutaneous manifestations are not one of the main prognostic determinants in Behcet's disease, they seem to impair the quality of life of the patients. In this review, mucocutaneous symptoms of Behcet's disease are outlined.

Key Words: Behcet's disease; Mucocutaneous lesions;Skin. 


\section{Giriş}

Hulusi Behçet tarafindan tekrarlayan oral aftöz ülserler, genital ülserler ve üveitle karakterize üçlü semptom bileşeninden oluşan bir tablo olarak tanımlanan Behçet hastalığı (BH) (1), mukokutan ve göz tutulumu dışında eklemler, pulmoner, gastrointestinal, ürogenital, kardiyak, damar ve sinir sistemlerinin de tutulabildiği, temel patolojisi vaskülit olan kronik sistemik bir inflamatuar hastalık olarak kabul edilmektedir (2-7).

Yapılan tüm araştırmalara rağmen etyolojisi hala bilinmemektedir. Ancak bu araştırmalarda hastalığın patogenezi ile ilgili önemli ipuçları elde edilmiş, doğal ve adaptif immünitenin bu süreçte birlikte rol oynadığı ile ilgili güçlü deliller ortaya çıkarılmıştır. Bu yönü ile ele alındığında $\mathrm{BH}$ ile otoimmün ve otoinflamatuar hastalıklar arasında ortak immünolojik mekanizmalar olduğu görülmüş, bu durumun klinik bulgulara da yansıdığı anlaşılmıştir.

Diğer taraftan patogenezindeki bu zenginlik, BH'nın otoinflamatuar hastalıklar ya da karışık grup immünolojik hastalıklar başlığı altında sınıflandırılmasına neden olmuştur $(8,9)$.

$\mathrm{BH}$ için patognomonik laboratuar bulguları olmadığından tanı öykü ve tipik klinik bulgulara dayanmaktadır. Tanısal amaçla ortaya konulan değişik tanı kriterlerin den en fazla tercih edileni 1990 yılında tanımlanmış olan, temel kriterleri mukokutanöz bulguların oluşturduğu Uluslararası Behçet Hastalığı Çalışma Grubu (10) kriterleridir (Tablo 1). Genellikle yaşamın ikinci on yılının sonlarına doğru başlayan hastalık, en sık olarak 2040 yaşları arasında görülmektedir $(6,7)$. Illk bulgunun ortaya çıkması ile tanı konulması arasındaki süre özellikle mukokutanöz tutulumu olanlarda 3 yılın üzerindedir (11). Olguların yaklaşık \%2-3'ünde hastalık çocukluk döneminde başlamaktadır (6). Kadın erkek dağılımı ile ilgili sonuçlar değişkendir. Akdeniz ülkelerinde erkeklerde daha sık olduğu bildirilmekle birlikte, kadın erkek oranı aynı olan bildiriler de bulunmaktadır (12). Türkiye'nin farklı bölgelerinde yapılan prevalans çalışmalarında 2-42/10.000 arasında değişen oranlar bildirilmiştir (13-17). BH, erkeklerde ve erken başlangıç yaşı gösterenlerde daha şiddetli bir klinik seyir izlemektedir (18). Papülopüstüler lezyonlar ile göz, vasküler, nörolojik ve pulmoner sistemlerin tutulumunun erkeklerde, genital ülser ve eritema nodozumun ise kadınlarda daha sık görüldüğü bildirilmiştir (19). Pediatrik olgularda ise klinik özellikler erişkinlerle benzerlik göstermektedir (20).

Mukokutanöz bulgular BH tanı kriterleri arasında en önemlileridir ve hastalığın erken tanısı için değerlidirler.

Tablo1. Uluslararası Behçet Hastalığı Çalışma Grubu tanı kriterleri*(10).

Tekrarlayan oral ülserler 1 yıl içinde en az 3 kez tekrarlayan, doktor veya hasta tarafindan gözlenen minör, major veya herpetiform ülser

Yukarıdaki kritere ek olarak aşağıdaki kriterlerden en az ikisi

Tekrarlayan genital ülser Hasta veya hekim tarafindan gözlenen genital ülser veya skar oluşumu

Göz lezyonları Anterior, posterior üveit, retinal vaskülit

Deri lezyonları Eritema nodozum, psödofollikülit, papülopüstüler lezyonlar veya akneiform nodüller

Paterji testi pozitifliği 24. ve 48 saatte oluşan papülopüstüler lezyonlar

*Bulgular herhengi başka bir klinik açıklama yoksa anlamlıdır. 


\section{ORAL ÜLSERLER}

BH'nın en karakteristik lezyonunu oluşturan ve tüm hastalarda gözlenen oral ülserler olguların \%86'sında ilk bulgu olarak ortaya çıkarlar. Ağrılı ve yineleyici özellikteki bu lezyonlar morfolojik olarak rekürren aftöz stomatite benzemekle birlikte, daha yaygın ve sık tekrarlayıcı bir klinik gösterirler. Genellikle dil, dudak, ve yanak mukozasının keratinizasyon göstermeyen bölgelerine, daha az sıklıkta da uvula, farinks gibi ağız posterior alanlarına yerleşirler; değişik çaplarda gözlenmeleri önemli özellikleridir. Ülserler oval-yuvarlak şekilli, çevresinde hiperemik inflamatuvar bir halo olan, grimsi beyaz tabanlı bir görünüm sergilerler. Lokal travmalar yeni lezyonların gelişimini tetikleyebilir. Ayrıca yılda en az 3 kez yineleme özelliği gösteren oral ülserler, BH tanısı için olmazsa olmaz kriteri oluşturur$\operatorname{lar}(2,5,6,21,22)$.

Oral ülserler çaplarına göre üç grupta sınıflandırılır. Çapları 1cm'den küçük olan (2-6 mm) ve 1-2 haftada sikatris bırakmadan iyileşen, tek veya çok sayıda gözlenen yüzeysel erode alanları olan minör aftöz ülserler hastalığın seyrinde en sık görülen lezyonlardır. Çapları $1 \mathrm{~cm}$ 'den büyük, derin yerleşimli major aftöz ülserler, 2-6 hafta veya daha uzun sürede genellikle sikatris ile iyileşirler. Küçük (2-3 mm) çaplı, sayıları 100'e ulaşan ve birbirleriyle birleşme eğilimindeki herpetiform aftöz ülserler en az görülen oral lezyonlardır; sikatris bırakmadan kısa sürede iyileşirler $(2,3,6)$.

BH'da oral ülserlerin ayırıcı tanısında rekürren aftöz stomatit nedenleri, travmatik ülserler, enfeksiyon ve ilaçlara bağlı oluşan ülserler, hematolojik hastalıklar, Reiter sendromu, gastrointestinal hastalıklar, pemfigus vulgaris, eroziv liken planus, eritema multiforme düşünülmelidir (23).

\section{GENITAL ÜLSERLER}

$\mathrm{BH}^{\prime}$ nin başlıca bulgularından olan genital ülserler olguların \%60-90'ında gözlenir $(7,19)$. Başlangıç bulgusu olarak ortaya çıkmaları nadirdir. Genellikle papül veya püstül olarak başlayıp hızla ülser şekline dönüşürler; ödemli bir sınırı olan, tabanı sarı fibrinle kaplı bir yitim alanı niteliğindedir. Ağrılı ve yineleyici özellikteki lez- yonlar en sık skrotum ve vulvada yerleşmekle birlikte erkeklerde inguinal bölge, pubis ve perine; kadınlarda ise labiumlar, serviks ve vajen lokalizasyonunda da gözlenebilirler. Ayrıca perianal yerleşim de görülebilmektedir. Kadınlarda genital ülserler erkeklerden daha büyük çaplı olabilir; vajinal ülserasyonlar sonrası mesane ve üretral fistüller, idrar yapmada zorluk, disparoni ve yürüme sorunları görülebilir. Genital ülserler yaklaşık 10-30 günde genellikle sikatris bırakarak iyileşirler. Sikatris varlığının tanı için önemi vurgulanmaktadır $(2,3,6,7)$.

BH'da görülen genital ülserlerin ayırıcı tanısında enfeksiyöz nedenler, ilaçlar, eroziv liken planus, büllü hastaııklar dışlanmalıdır (23).

\section{PAPÜLOPÜSTÜLER LEZYONLAR}

Sık izlenen deri bulguları arasında yer alan papülopüstüler lezyonlar eritemli zeminde follikülit veya akne benzeri lezyonlarla karakterize olup, papül halinde başlayan lezyonlar 24-48 saatte püstüle dönüşürler (24). Papülopüstüler lezyonlar genellikle farklı deri alanlarında eş zamanlı bulunurlar. En sık lokalizasyonları sırt, yüz ve göğüs ön yüzdür. Sırtta izlenen papül ve püstüller genellikle akneye benzer ve klinik olarak akne vulgaristen ayrılamayabilirler. Diğer tip papüller ekstremitelerde izlenirler ve 2-4 günde merkezinde steril püstüller oluşur. Püstülün çevresinde ise genellikle eritemli halo bulunur (6). Uluslararası Behçet Hastalığı Çalışma Grubu psödofollikülit, papülopüstüler lezyonlar ve akneiform lezyonların duyarlılığını \%70, özgüllügünü ise \%76 olarak bildirmiştir (25).

\section{ERITEMA NODOZUM BENZERI LEZYONLAR}

BH'da \%47.6-55.3 oranlarında görülen eritema nodozum benzeri lezyonlar, klinik olarak ağrılı, kırmızı-mor renkli nodüllerle karakterizedirler $(11,21,26)$. Daha çok kadınlarda ve alt ekstremitelerde görülmekle birlikte kollar, boyun ve yüzde de gözlenebilirler.Sayı olarak değişkenlik gösterirler; ortalama 2-3 hafta içinde ülserasyon göstermeden pigmentasyon bırakarak iyileşirler $(2,3,6,7)$. 
Klinik olarak klasik eritema nodozumdan ayırt edilemeyen bu lezyonlarda histopatolojik olarak nötrofilik vasküler bir reaksiyon veya vaskülit izlenir (27). Yine vaskülit yanında septal veya lobüler pannikülit, yağ nekrozu ve mikroapse oluşumu gibi ikincil bulgular da bildirilmiştir (28).

\section{YÜZEYEL TROMBOFLEBIT}

BH'da vasküler tutulum sıklıkla venöz tutulum şeklinde olup hastaların 1/3'ünde görülür. Vasküler komplikasyonlar içinde tromboflebit en sık tutulum şeklidir. Tromboflebit hastaların \%10-37 kadarında izlenir $(29,30)$. Genellikle büyük safen vende izlenen yüzeysel tromboflebitler palpabıl ağrılı subkutan nodüller veya ip şeklinde sert kızarıklık şeklinde klinik görüntü veren lezyonlardır. Proksimalden distale yayılma eğiliminde olan bu lezyonlar BH tanı kriterleri içinde yer almamaktadırlar. Gezici olmaya eğilimli olan yüzeysel gezici tromboflebit tabloları genellikle erkekte izlenir $(6,31)$.

\section{EKSTRAGENITAL ÜLSER}

Behçet hastalarının yaklaşık \%3'ünde görülmektedir. Klinik olarak tekrarlayıcıdırlar ve sikatris ile iyileşirler. Genellikle yerleşim yeri; meme, bacak, aksilla, ayaklarda interdigital bölge, inguinal bölge ve boyundur. Bu lezyonlar BH'nin en karakteristik ve spesifik lezyonlarından kabul edilmektedir $(31,32)$.

\section{PATERJi TESTi}

Çoğu BH'da tespit edilen paterji fenomeni minör kutanöz travmaya hiperreaktif cevap olarak tanımlanır. Paterji testi steril koşullar altında ön kol fleksör yüzüne uygulanır. Testin $20 \mathrm{G}$ enjektör iğnesi ile ve en az iki ayrı noktaya pikür yapılarak uygulanması önerilmektedir. Reaksiyonun gelişebilmesi için pikürün dermise kadar inecek derinlikte ve 45 derecelik açıyla uygulanması gerekmektedir. Behçet hastalarında palpasyonla hissedilebilen ve genellikle eritemli bir halo ile çevrili 1-2 mm çaplı bir papül oluşur. Bu lezyon papül olarak kalabileceği gibi 1-5 mm'lik püstüle dönüşebilir. Uluslararası Behçet Hastalığı Çalışma Grubu paterji testinin duyarlılığını \%58, özgüllüğünü ise $\% 90$ olarak bildirmiş- tir. Çoğunlukla hücresel immünitenin patogenezde rol oynadığı düşünülür. Paterji testinin pozitiflik oranları \%6-71 arasında değişmektedir. Akdeniz ve Ortadoğu ülkelerinde yüksek pozitiflik, Uzak Doğu ülkelerinde göreceli olarak düşük pozitiflik, Bat ülkelerinde oldukça düşük pozitiflik oranları bildirilmektedir $(2,25,31)$.

\section{SWEET SENDROMU BENZERI LEZYONLAR}

Behçet hastalarında deri bulgusu olarak Sweet benzeri lezyonların görülmesinin yanında bazı olgularda Sweet sendromu ve $\mathrm{BH}$ beraberliği de görülmektedir (33-35). Her iki hastalığın da etyolojisi henüz netleşmemiş olmakla beraber, herpes simplex virüs tip 1 'in benzer olarak patogenezlerinde rolü olabileceği düşünülmektedir (36). Yapılan genetik çalışmalarda ise hastalıklardan sorumlu HLA tiplerinin farklı olduğu görülmüştür (37).

Sweet sendromu tanısı konulamayan Behçet hastalarında görülen Sweet sendromu benzeri lezyonlar ise Behçet selüliti olarak tanımlanabilir. Eritematöz, ödematöz, ağrılı lezyonlar şeklinde izlenir. Sıklıkla alt ekstremitelerde olmak üzere nadir olarak üst ekstremite ve yüzde gözlenebilir. Lezyondan alınan biyopsiler Sweet sendromunda görülen nötrofilik infiltrasyondan farklı olarak vaskülit ile uyumludur. enfeksiyona sekonder selülit ve yüzeyel tromboflebit ile ayrımını yapmak önemlidir (38).

\section{PYODERMA GANGRENOZUM}

Pyoderma gangrenozum ve $\mathrm{BH}$ paterji pozitifliği, histolojik olarak nötrofilik vasküler reaksiyon göstermesi ile klinik ve histolojik olarak benzer özellikler gösterirler. Literatürde $\mathrm{BH}$ 'na eşlik eden püstüler, ülseratif, büllöz ve vejetatif pyoderma gangrenozum formları bildirilmiştir $(39,40)$.

\section{DIĞER DERI BULGULARI}

Eritema induratum benzeri lezyonlar Behçet hastalarında nadir olarak gözlenen kırmızı, mavi, endüre, subkutan nodüllerdir. Süpüratif pannikülit oldukça nadir gözlenen ateş ve nodüller ile karakterizedir. Bu nodüller fistüle olarak direne olur ve yerlerinde skar bırakarak iyileşirler (38). 
Staz ülserleri Behçet hastalarında kronik venöz yetmezliğe bağlı olarak sıklıkla alt ektremitede gözlenir. Hastalarda bu ülserelerin vaskülit ve pyoderma gangrenozumdan ayrımının yapılması önemlidir (41).

$\mathrm{BH}$ ve Raynoud Fenomeni birlikteliği Önder ve ark. tarafindan gösterilmiştir (42).

Behçet hastalarında sık gözlenen deri bulgularının yanında eritema multiforme, büllöz nekrotizan vaskülit, pernio benzeri lezyonlar, lupus birlikteliği literatürde olgu sunumları şeklinde yer almaktadır (43).

Sonuç olarak mukokutanöz bulguların $\mathrm{BH}^{\prime}$ nda hem tanı koydurucu hem de en sık rastlanan bulgular olduğu ve hastaların yaşam kalitesini önemli ölçüde etkiledikleri görülmektedir. Erken dönemde tanı koydurucu olan bu bulguların iyi bilinmesi hastalığın seyri sırasında ortaya çıkabilecek komplikasyonların önlenmesinde büyük önem taşımaktadırlar.

\section{KAYNAKLAR}

1. Behçet $H$. Uber rezidivierende, aphthose, dürch ein Virus verursachte Geshwure am Munde, am Auge und an den Genitalien. Dermatologische Wochenschrift. 1937;36(1):1152-7.

2. Alpsoy E. Behçet hastalığının deri ve mukoza belirtileri. Türkderm. 2003;37(2):92-9.

3. Onder M, Gürer MA. The multiple faces of Behçet's disease and its aetiological factors. J Eur Acad Dermato Venereol. 2001;15(2):126-36.

4. Bang D. Clinical spectrum of Behçet's disease. J Dermatol. 2001;28(11):610-3

5. Lee LA. Behçet disease. Semin Cutan Med Surg. 2001;20(1):53-7.

6. Saylan T, Mat C, Fresko I, Melikoğlu M. Behçet's disease in the Middle East. Clin Dermatol. 1999;17(2):209-23.

7. Sakane T, Takeno M, Suzuki N, Inaba G. Behçet's disease. N Engl J Med. 1999;341(17):1284-91.

8. Hedayatfar A. Behçet's Disease: Autoimmune or autoinflammatory? J Ophthalmic Vis Res. 2013;8(3):291-3.

9. Muşabak U. Otoinflamatuar bir hastalık olarak Behçet hastalığı. Turkiye Klinikleri J Dermatol-Special Topics. 2011;4(4):32-44.

10. International Study Group for Behçet's Disease. Criteria for diagnosis of Behçet's disease. Lancet. 1990;335(8697):1078-80.
11. Alpsoy E, Donmez L, Bacanli A, Apaydin C, Butun $B$. Review of the chronology of clinical manifestations in 60 patients with Behçet's disease. Dermatology. 2003;207(4):354-6.

12. Önder M, Gürer MA. Ülkemizde Behçet hastalığı epidemiyolojisi. Turkiye Klinikleri J Int Med Sci. 2007;3(9):4-7.

13. Demirhindi $O$, Yazıcı H, Binyıldız P, Dayıoğlu N, Tüzün $\mathrm{Y}$, Altaç M, et al. Silivri Fener Köyü ve yöresinde Behçet Hastalığı sıklığı ve bu hastalığın toplum içinde taranmasında kullanılabilecek bir yöntem. Cerrahpaşa Tıp Fak Derg. 1981;12(1):509-14.

14. Yurdakul S, Günaydın I, Tüzün Y, Tankurt N, Pazarlı H, Özyazgan $\mathrm{Y}$, et al. The prevalence of Behcet's syndrome in a rural area in northern Turkey. The Journal of Rheumatology. 1988;15(5):820-2.

15. Idil A, Gürler A, Boyvat A, Caliskan D, Ozdemir O, Isik A, et al. The prevalence of Behçet's disease above the age of 10 years. The results of a pilot study conducted at the Park Primary Health Care Center in Ankara, Turkey. Ophthalmic Epidemiology. 2002;9(5):325-31.

16. Azizlerli G, Köse AA, Sarica R, Gül A, Tutkun IT, Kulaç M, et al. Prevalence of Behçet's disease in Istanbul, Turkey. International Journal of Dermatology. 2003;42(10):803-6. 17. Cakir N, Dervis E, Benian O, Pamuk ON, Sonmezates $\mathrm{N}$, Rahimoglu R, et al. Prevalence of Behçet's disease in rural western Turkey: a preliminary report. Clinical and Experimental Rheumatology. 2004;22(34):53-5.

18. Yazici H, Tüzün Y, Pazarli H, Yurdakul S, Ozyazgan Y, Ozdoğan $\mathrm{H}$, et al. Influence of age of onset and patient's sex on the prevalence and severity of manifestations of Behçet's syndrome. Ann Rheum Dis. 1984;43(6):783-9.

19. Tursen U, Gurler A, Boyvat A. Evaluation of clinical findings according to sex in 2313 Turkish patients with Behçet's disease. Int J Dermatol. 2003;42(5):346-51.

20. Borlu M, Ukşal U, Ferahbaş A, Evereklioglu C. Clinical features of Behçet's disease in children. Int J Dermatol. 2006;45(6):713-6.

21. Bang D, Yoon KH, Chung HG, Choi EH, Lee ES, Lee S. Epidemiological and clinical features of Behçet's disease in Korea. Yonsei Med J. 1997;38(6):428-36.

22. Magro $\mathrm{CM}$, Crowson AN. Cutaneous manifestations of Behçet's disease. Int J Dermatol. 1995;34(3):159-65.

23. Bulur I, Önder M. Behçet hastalığında deri bulguları. Turkiye Klinikleri J Dermatol. 2011;4(4):4-9.

24. Alpsoy E, Aktekin M, Er H, Durusoy C, Yilmaz E. A randomized, controlled and blinded study of papulopustular lesions in Turkish Behçet's patients. Int J Dermatol. 1998;37(11):839-42. 
ÇÖLGEÇEN ve ark. Behçette Deri ve Mukoza
Bozok Tip Derg 2014,4(2):53-8

Bozok Med J 2014;4(2):53-8
25. International Study Group for Behçet's Disease. Evaluation of diagnostic ('classification') criteria in Behçet's disease-towards internationally agreed criteria. $\mathrm{Br}$ J Dermatol. 1992;31(5):299-308.

26. Hamuryudan V. Behçet hastalığı. Turkiye Klinikleri J Int Med Sci. 2005;1(25):1-72.

27. Ghate JV, Jorizzo JL. Behçet's disease and complex aphthosis. J Am Acad Dermatol. 1999;40(1):1-18.

28. Kim B, LeBoit PE. Histopathologic features of erythema nodosum--like lesions in Behçet disease: a comparison with erythema nodosum focusing on the role of vasculitis. Am J Dermatopathol. 2000;22(5):379-90.

29. Thomas I, Helmold ME, Nychay S. Behçet's disease presenting as superior vena cava syndrome. J Am Acad Dermatol. 1992;26(5 Pt 2):863-5.

30. Kuzu MA, Ozaslan C, Köksoy C, Gürler A, Tüzüner A. Vascular involvement in Behçet's disease: 8-year audit. World J Surg. 1994;18(6):948-54.

31. Lee ES, Bang D, Lee S. Dermatologic manifestation of Behçet's disease. Yonsei Med J. 1997;38(6):380-9.

32. Azizlerli G, Ozarmağan G, Ovül C, Sarica R, Mustafa SO. A new kind of skin lesion in Behçet's disease: extragenital ulcerations. Acta Derm Venereol. 1992;72(4):286.

33. Hassikou H, Tabache F, Baaj M, Safi S, Hadri L. Sweet's syndrome in Behçet's disease. Joint Bone Spine. 2007;74(5):495-6.

34. Wu F, Luo X, Yuan G. Sweet's syndrome representing a flare of Behçet's disease. Clin Exp Rheumatol. 2009;27(2 Suppl 53):88-90.

35. Karadoğan SK, Başkan EB, Alkan G, Saricaoğlu H, Tunali S. Generalized Sweet syndrome lesions associated with Behçet disease: a true association or simply co-morbidity? Am J Clin Dermatol. 2009;10(5):331-5.

36. Lee MS, Barnetson RS. Sweet's syndrome associated with Behçet's disease. Australas J Dermatol. 1996;37(2):99101.

37. Mizoguchi M, Chikakane K, Goh K, Asahina Y, Masuda K. Acute febrile neutrophilic dermatosis (Sweet's syndrome) in Behçet's disease. Br J Dermatol. 1987;116(5):727-34.

38. Davatchi F, Shahram F, Chams-Davatchi C, Shams H, Nadji A, Akhlaghi M, et al. Behcet's disease: From East to West. Clin Rheumatol. 2010;29(8):823-33.

39. Kim JW, Park JH, Lee D, Hwang SW, Park SW. Vegetative pyoderma gangrenosum in Behçet's disease. Acta Derm Venereol. 2007;87(4):365-7.

40. Nakamura T, Yagi H, Kurachi K, Suzuki S, Konno H. Intestinal Behcet's disease with pyoderma gangrenosum: A case report. World J Gastroenterol. 2006;12(6):979-81.
41. Calamia KT, Schirmer M, Melikoglu M. Major vessel involvement in Behçet's disease: An update. Curr Opin Rheumatol. 2011;23(1):24-31.

42. Onder M, Ozden MG, Aksakal AB, Akçali D, Babacan A, Atasever T. Raynaud phenomenon and Behçet disease: diagnosis with technetium Tc 99m methylene diphosphonate bone scan and treatment with continuous sympathetic block. Arch Dermatol. 2002;138(5):698-9. 43. Kerkeni N(1), Zaraa I, Ayachi J, El Euch D, Mokni M, Ben Osman A. Behçet's disease: A profile of mucocutaneous features. Acta Dermatovenerol Alp Panonica Adriat. 2010;19(2):11-5. 